\author{
Correspondence \\ Peter Kämpfer \\ peter.kaempfer@umwelt. \\ uni-giessen.de
}

\section{Microbacterium arthrosphaerae sp. nov., isolated from the faeces of the pill millipede Arthrosphaera magna Attems}

\author{
P. Kämpfer, ${ }^{1}$ P. D. Rekha, ${ }^{3}$ P. Schumann, ${ }^{2}$ A. B. Arun, ${ }^{3}$ \\ Chiu-Chung Young, ${ }^{4}$ Wen-Ming Chen ${ }^{5}$ and K. R. Sridhar ${ }^{6}$
}

\author{
${ }^{1}$ Institut für Angewandte Mikrobiologie, Justus-Liebig-Universität Giessen, D-35392 Giessen, \\ Germany \\ ${ }^{2}$ DSMZ - Deutsche Sammlung von Mikroorganismen und Zellkulturen, D-38124 Braunschweig, \\ Germany \\ ${ }^{3}$ Yenepoya Research Center, Yenepoya University, Deralakatte, Mangalore, Karnataka, India \\ ${ }^{4}$ Department of Soil and Environmental Sciences, College of Agriculture and Natural Resources, \\ National Chung-Hsing University, Taiwan, ROC \\ ${ }^{5}$ Laboratory of Microbiology, Department of Seafood Science, National Kaohsiung Marine \\ University, Taiwan, ROC \\ ${ }^{6}$ Microbiology and Biotechnology, Department of Biosciences, Mangalore University, \\ Karnataka, India
}

\begin{abstract}
A Gram-reaction-positive, rod-shaped bacterium, designated strain CC-VM- $\mathrm{Y}^{\top}$, was isolated from the faeces of the pill millipede Arthrosphaera magna Attems from India and was subsequently studied to determine its taxonomic position. Based on 16S rRNA gene sequence similarities, the isolate clearly grouped with members of the genus Microbacterium. On the basis of pairwise comparisons of the $16 \mathrm{~S}$ rRNA gene sequences, strain $\mathrm{CC}-\mathrm{VM}-\mathrm{Y}^{\top}$ was most closely related to Microbacterium insulae DS-66 ${ }^{\top}$ (98\%), Microbacterium hydrocarbonoxydans DSM $160809^{\top}$ $(97.8 \%)$ and Microbacterium hominis NBRC $15708^{\top}$ (97.9\%). The peptidoglycan contained the amino acids ornithine (Orn), alanine (Ala), glycine (Gly), homoserine (Hsr) and glutamic acid (Glu) in an approximate molar ratio of $1.0: 0.8: 2.2: 0.8: 0.3$. In addition, substantial amounts of threo-3-hydroxy glutamic acid (Hyg) were detected, which is characteristic of peptidoglycan type B2 $\beta$. The acyl type of the peptidoglycan was glycolyl. The menaquinones of strain CC-VM-Y ${ }^{\top}$ were MK-13 (72\%), MK-12 (25\%) and MK-11 (3\%). The polar lipids consisted of phosphatidylglycerol, diphosphatidylglycerol, one unknown phospholipid and one unknown glycolipid. The fatty acid profile comprised anteiso- $C_{15: 0}$, iso- $C_{16: 0}$ and anteiso- $C_{17: 0}$ as the major fatty acids, which was congruent with fatty acid profiles of other members of the genus Microbacterium. The results of physiological and biochemical tests as well as DNA-DNA hybridizations with the most closely related species, M. insulae, M. hydrocarbonoxydans and M. hominis, revealed clear phenotypic and genotypic differences between strain CC-VM- ${ }^{\top}$ and other members of the genus Microbacterium. Based on these results, strain CC-VM- ${ }^{\top}$ $\left(=\mathrm{DSM} 22421^{\top}=\mathrm{CCM} 7681^{\top}\right)$ represents a new species of the genus Microbacterium, for which the name Microbacterium arthrosphaerae sp. nov. is proposed.
\end{abstract}

Abbreviations: DPG, diphosphatidylglycerol; GL, glycolipid; Hyg, threo-3hydroxy glutamic acid; PG, phosphatidylglycerol; PL, phospholipid; pNA, para-nitroanilide; pNP, para-nitrophenyl.

The GenBank/EMBL/DDBJ accession number for the 16S rRNA gene sequence of strain CC-VM- $Y^{\top}$ is FN870023.

One supplementary figure and one supplementary table are available with the online version of this paper.
The genus Microbacterium was proposed by Orla-Jensen (1919) and the genus description was emended by Collins et al. (1983) and later by Takeuchi \& Hatano (1998), who proposed the unification of the genera Microbacterium and Aureobacterium. At the time of writing, the genus comprised $>70$ species with validly published names. Microbacteria are typically Gram-positive, non-sporeforming rods, which often produce yellow-pigmented 
colonies. Members of the genus Microbacterium have been isolated from a wide variety of environmental sources, including soil, water and plants as well as from steep liquor, milk products and clinical specimens.

Here, we describe the phenotypic and genotypic properties of a novel strain isolated from the faeces of the pill millipede Arthrosphaera magna Attems from India.

Strain CC-VM-Y ${ }^{\mathrm{T}}$ was obtained from faeces of a pill millipede by culturing on nutrient agar (Oxoid) at $30{ }^{\circ} \mathrm{C}$ for $48 \mathrm{~h}$. The isolate was preserved at $-80{ }^{\circ} \mathrm{C}$ in nutrient broth (NB; Oxoid) with $20 \%(\mathrm{v} / \mathrm{v})$ glycerol or by lyophilization.

Morphological properties, Gram-staining and cell morphology were tested by using phase-contrast microscopy as described previously (Kämpfer \& Kroppenstedt, 2004).

The 16S rRNA gene sequence was determined as described by Young et al. (2005). Multiple sequence alignment and analysis of the data were performed using the software package MEGA version 4 (Tamura et al., 2007). Genetic distance calculations (distance options according to the
Kimura-2 model) and clustering using the neighbourjoining (Fig. 1) and maximum-parsimony (results not shown) methods were performed by using bootstrap values based on 1000 replications. The 16S rRNA gene sequence of strain CC-VM-Y ${ }^{\mathrm{T}}$ was a continuous stretch of $1339 \mathrm{bp}$. On the basis of pairwise comparisons of 16S rRNA gene sequences using the EzTaxon program (Chun et al., 2007), strain CC-VM-Y ${ }^{\mathrm{T}}$ showed 98.0, 97.8 and $97.9 \%$ sequence similarity to Microbacterium insulae DS- $66^{\mathrm{T}}$, Microbacterium hydrocarbonoxydans DSM $160809^{\mathrm{T}}$ and Microbacterium hominis NBRC $15708^{\mathrm{T}}$, respectively. 16s rRNA sequence similarities to all other species of the genus Microbacterium were $<97.0 \%$. The peptidoglycan of strain CC-VM-Y ${ }^{\mathrm{T}}$ was analysed by using the methods of Schleifer \& Kandler (1972), Schleifer (1985), MacKenzie (1987) and Groth et al. (1996). The acyl type of the peptidoglycan was determined according to Uchida et al. (1999). Polar lipids and menaquinones were studied by using the methods of Groth et al. (1996). Amino acids were analysed by GC (GC 14A, Shimadzu) and GC-MS (320-MS Quadrupole GC/MS, Varian) of the $N$-heptafluorobutyryl amino acid

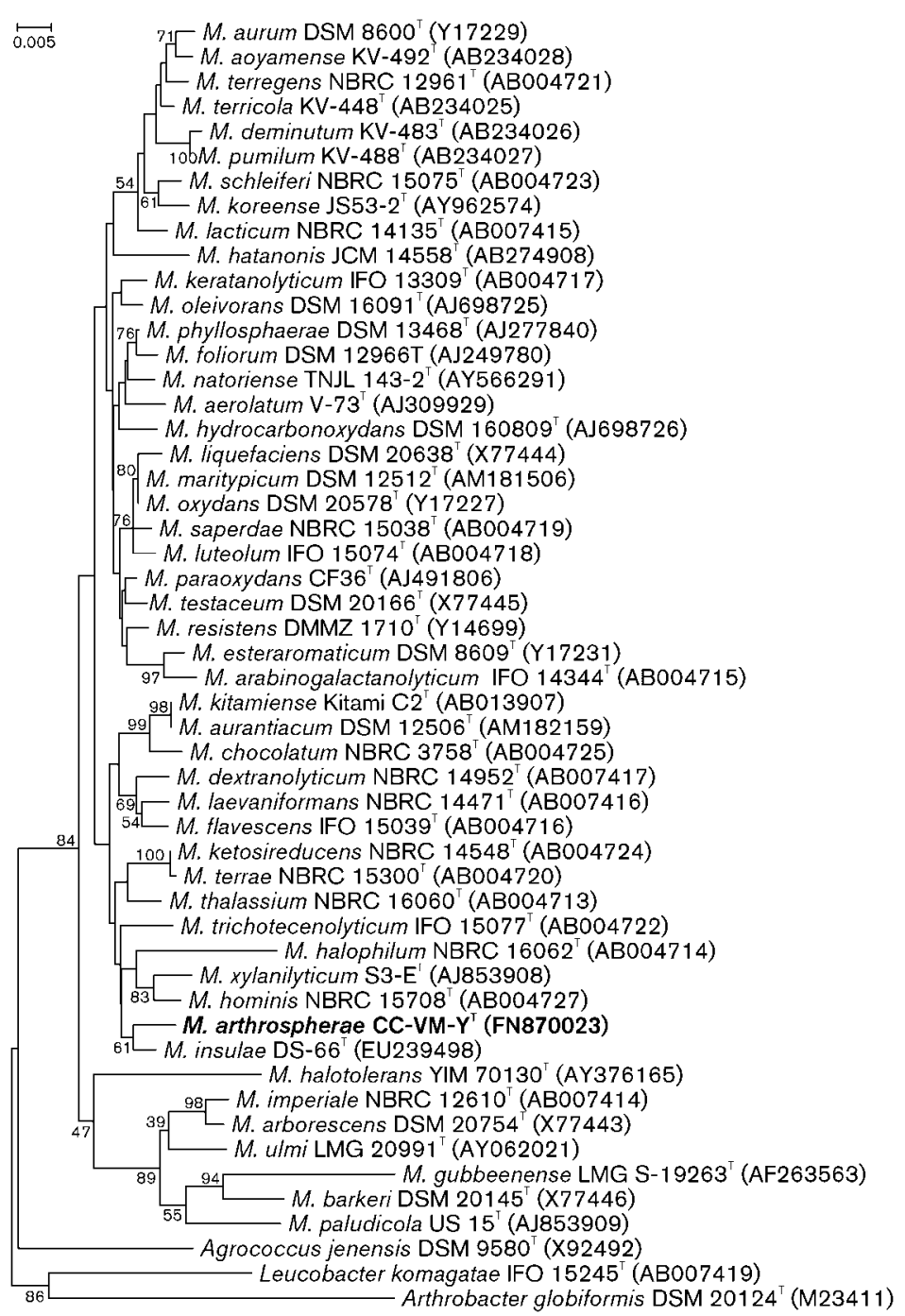

Fig. 1. Phylogenetic tree based on $16 \mathrm{~S}$ rRNA gene sequences, obtained from the GenBank/ EMBL/DDBJ database, of type strains of selected species of the genus Microbacterium. Multiple alignments, distance calculations (distance options according to the Kimura-2 model) and clustering with the neighbour-joining method were performed by using the software package MEGA version 4 (Tamura et al., 2007). Bootstrap values $>50 \%$, based on 1000 replications, are listed at branch points. Bar, 0.01 substitutions per nucleotide position. 
isobutyl esters (MacKenzie, 1987; Groth et al., 1996). Hydrolysates (treated with $4 \mathrm{M} \mathrm{HCl}$ at $100{ }^{\circ} \mathrm{C}$ for $16 \mathrm{~h}$ ) of the purified peptidoglycan of strain $\mathrm{CC}-\mathrm{VM}-\mathrm{Y}^{\mathrm{T}}$ contained the amino acids ornithine (Orn), alanine (Ala), glycine (Gly), homoserine (Hsr) and glutamic acid (Glu) in an approximate molar ratio of $1.0: 0.8: 2.2: 0.8: 0.3$. In addition, a substantial amount of threo-3-hydroxy glutamic acid (Hyg) was detected, which is characteristic of peptidoglycan type B2 $\beta$ (Schleifer \& Kandler, 1972) (type B6 according to http://www.dsmz.de/microorganisms/main.php?content_id=35). The acyl type of the peptidoglycan was glycolyl. The menaquinones of strain CC-VM-Y $\mathrm{Y}^{\mathrm{T}}$ were MK-13 $(72 \%)$, MK-12 (25\%) and MK-11 (3\%), similar to those found in other species of the genus Microbacterium ( $\mathrm{Li}$ et al., 2005; Young et al., 2010). The polar lipids comprised phosphatidylglycerol (PG), diphosphatidylglycerol (DPG), one unknown phospholipid (PL) and one unknown glycolipid (GL) (Supplementary Fig. S1, available in IJSEM Online). These major polar lipids have been detected in numerous species of the genus Microbacterium (Zlamala et al., 2002; Rivas et al., 2004; Kim et al., 2005; Buczolits et al., 2008; Park et al., 2006; Young et al., 2010) and are listed in the emended genus description of Takeuchi \& Hatano (1998).

Fatty acid analysis was performed according to the method of Kämpfer \& Kroppenstedt (1996). The fatty acid profile of strain CC-VM-Y ${ }^{\mathrm{T}}$ was very similar to those of closely related members of the genus Microbacterium (Supplementary Table S1), all of which contained anteiso$\mathrm{C}_{15: 0}$, iso- $\mathrm{C}_{16: 0}$ and anteiso- $\mathrm{C}_{17: 0}$ as major fatty acids.

Results of comparative physiological characterization tests (Kämpfer et al., 1991) on strains CC-VM-Y ${ }^{\mathrm{T}}, M$. insulae CCUG $54523^{\mathrm{T}}, M$. hominis DSM $12509^{\mathrm{T}}$ and M. hydrocarbonoxydans DSM $16089^{\mathrm{T}}$, using identical test conditions, are given in Table 1 and in the species description. DNA-DNA hybridization experiments were performed with strain CC-VM-Y $\mathrm{Y}^{\mathrm{T}}$ and $M$. insulae CCUG $54523^{\mathrm{T}}, M$. hominis DSM $12509^{\mathrm{T}}$ and M. hydrocarbonoxydans DSM $16089^{\mathrm{T}}$ according to the method of Ziemke et al. (1998). Strain CC-VM-Y $\mathrm{Y}^{\mathrm{T}}$ showed relatedness values of $44.1 \%$ with $M$. insulae CCUG $54523^{\mathrm{T}}$ (39.9\% reciprocal analysis), $38.2 \%$ with $M$. hominis DSM $12509^{\mathrm{T}}(29.1 \%$ reciprocal analysis) and $34.9 \%$ with $M$. hydrocarbonoxydans DSM $16089^{\mathrm{T}}$ (31.9\% reciprocal analysis).

Based on differences in peptidoglycan types, quinone systems, fatty acid and polar lipid profiles and observed phenotypes between the strains as well as on the results of the DNA-DNA pairing studies and 16S rRNA gene analyses, strain CC-VM-Y ${ }^{\mathrm{T}}$ represents a novel species of the genus Microbacterium, for which the name Microbacterium arthrosphaerae sp. nov. is proposed.

\section{Description of Microbacterium arthrosphaerae sp. nov.}

Microbacterium arthrosphaerae (ar.thro.spha.e'rae. N.L. gen. n. arthrosphaerae of Arthrosphaera, the genus name
Table 1. Assimilation of substrates by strain $C C-V M-Y^{\top}$ and type strains of the most closely related species of the genus Microbacterium

Strains: 1 , CC-VM-Y $\mathrm{Y}^{\mathrm{T}} ; 2$, M. insulae CCUG $54523^{\mathrm{T}} ; 3$, M. hominis DSM $12509^{\mathrm{T}} ; 4$, M. hydrocarbonoxydans DSM $16089^{\mathrm{T}}$. All data was obtained from this study using methods according to Kämpfer et al. (1991). All strains hydrolysed aesculin, para-nitrophenyl (pNP)alpha-D-glucopyranoside, pNP- $\beta$-D-glucopyranoside pNP- $\beta$-D-xylopyranoside, pNP-phenyl-phosphonate, L-alanine-para-nitroanilide $(\mathrm{pNA})$ and L-proline-pNA. None of the strains hydrolysed pNP- $\beta$ D-glucuronide, pNP-phosphorylcholine, 2-deoxythymidine-5'-pNPphosphate and L-glutamate- $\gamma$-3-carboxy-pNA. All strains utilized the following as sole sources of carbon: L-arabinose, p-arbutin, cellobiose, D-fructose, D-glucose, D-galactose, D-mannose, maltose, sucrose, salicin, trehalose, D-xylose, D-mannitol, maltitol, pyruvate, L-aspartate and L-proline. None of the strains were able to utilize adonitol, myoinositol, cis-aconitate, trans-aconitate, adipate, azelate, mesaconate, suberate, phenylacetate, DL-3-hydroxybenzoate, phenylacetate and Ltryptophan. + , Positive; - , negative; (+), weakly positive.

\begin{tabular}{|lcccc|}
\hline Substrate & $\mathbf{1}$ & $\mathbf{2}$ & $\mathbf{3}$ & $\mathbf{4}$ \\
\hline Assimilation of: & & & & \\
N-Acetyl-D-galactosamine & $(+)$ & - & - & + \\
N-Acetyl-D-glucosamine & - & - & + & + \\
Gluconate & + & - & - & + \\
$\alpha$-Melibiose & + & $(+)$ & - & - \\
L-Rhamnose & - & $(+)$ & + & + \\
D-Ribose & + & - & - & + \\
D-Sorbitol & - & - & - & + \\
Putrescine & + & - & - & + \\
Acetate, propionate & $(+)$ & - & + & $(+)$ \\
4-Aminobutyrate & + & - & - & - \\
Citrate & + & - & + & + \\
Fumarate & - & + & + & + \\
Glutarate & + & - & - & + \\
DL-3-Hydroxybutyrate & $(+)$ & + & + & - \\
Itaconate & - & - & - & + \\
DL-Lactate & $(+)$ & - & + & + \\
L-Malate & - & + & + & - \\
Oxoglutarate & - & - & + & + \\
L-Alanine & + & - & + & + \\
$\beta$-Alanine & - & - & $(+)$ & + \\
L-Histidine & + & - & - & + \\
L-Leucine & + & $(+)$ & - & + \\
L-Ornithine & - & - & - & + \\
L-Phenylalanine & $(+)$ & - & - & - \\
L-Serine & - & - & - & + \\
4-Hydroxybenzoate & - & - & - & + \\
\hline & & & & \\
\hline
\end{tabular}

of the pill millipede Arthrosphaera magna, from which the type strain was isolated).

Cells are short rods $\sim 2-3 \times 1-1.2 \mu \mathrm{m}$ in size. Gramreaction-positive. Oxidase- and catalase-positive. Display aerobic respiratory metabolism. Good growth occurs after 3 days of incubation on Nutrient agar, R2A agar and tryptone soy agar at $25-30{ }^{\circ} \mathrm{C}$, forming yellow colonies. 
The peptidoglycan is of the type $\mathrm{B} 2 \beta$, with the interpeptide bridge D-Glu (Hyg)-Gly-D-Orn. The major quinones are MK-13 and MK-12 with minor amounts of MK-11. The polar lipid profile comprises PG, DPG, an unknown PL and an unknown GL. The major fatty acids are anteiso$\mathrm{C}_{15: 0}$, iso- $\mathrm{C}_{16: 0}$ and anteiso- $\mathrm{C}_{17: 0}$. Differential characteristics derived from physiological tests using identical conditions are given in Table 1.

The type strain, CC-VM-Y ${ }^{\mathrm{T}}\left(=\mathrm{DSM} \quad 22421^{\mathrm{T}}=\mathrm{CCM}\right.$ $7681^{\mathrm{T}}$ ), was isolated from the faeces of the pill millipede Arthrosphaera magna Attems from India.

\section{Acknowledgements}

We are grateful to Anika Wasner (DSMZ), Gundula Will and W. S. Huang for their excellent technical assistance and for performing $16 \mathrm{~S}$ rRNA gene sequencing and to Dr E. Falsen for providing the type strain of M. insulae.

\section{References}

Buczolits, S., Schumann, P., Valens, M., Rosselló-Mora, R. \& Busse, H.-J. (2008). Identification of a bacterial strain isolated from the liver of a laboratory mouse as Microbacterium paraoxydans and emended description of the species Microbacterium paraoxydans Laffineur et al. 2003. Int J Microbiol 48, 243-251.

Chun, J., Lee, J.-H., Jung, Y., Kim, M., Kim, S., Kim, B. K. \& Lim, Y.-W. (2007). EzTaxon: a web-based tool for the identification of prokaryotes based on $16 \mathrm{~S}$ ribosomal RNA gene sequences. Int J Syst Evol Microbiol 57, 2259-2261.

Collins, M. D., Jones, D. \& Kroppenstedt, R. M. (1983). Reclassification of Brevibacterium imperiale (Steinhaus) and "Corynebacterium laevaniformans" (Dias and Bhat) in a redefined genus Microbacterium (Orla-Jensen) as Microbacterium imperiale comb. nov. and Microbacterium laevaniformans nom. rev.; comb. nov. Syst Appl Microbiol 4, 65-78.

Groth, I., Schumann, P., Weiss, N., Martin, K. \& Rainey, F. A. (1996). Agrococcus jenensis gen. nov., sp. nov., a new genus of actinomycetes with diaminobutyric acid in the cell wall. Int J Syst Bacteriol 46, 234-239.

Kämpfer, P. \& Kroppenstedt, R. M. (1996). Numerical analysis of fatty acid patterns of coryneform bacteria and related taxa. Can $J$ Microbiol 42, 989-1005.

Kämpfer, P. \& Kroppenstedt, R. M. (2004). Pseudonocardia benzenivorans sp. nov. Int J Syst Evol Microbiol 54, 749-751.

Kämpfer, P., Steiof, M. \& Dott, W. (1991). Microbiological characterisation of a fuel-oil contaminated site including numerical identification of heterotrophic water and soil bacteria. Microb Ecol 21, 227-251.
Kim, K. K., Park, H. Y., Park, W., Kim, I. S. \& Lee, S.-T. (2005). Microbacterium xylanilyticum sp. nov., a xylan-degrading bacterium isolated from a biofilm. Int J Syst Evol Microbiol 55, 2075-2079.

Li, W.-J., Chen, H.-H., Kim, C.-J., Park, D.-J., Tang, S.-K., Lee, J.-C., Xu, L.-H. \& Jiang, C.-L. (2005). Microbacterium halotolerans sp. nov., isolated from a saline soil in the west of China. Int J Syst Evol Microbiol 55, 67-70.

MacKenzie, S. L. (1987). Gas chromatographic analysis of amino acids as the N-heptafluorobutyryl isobutyl esters. J Assoc Off Anal Chem 70, 151-160.

Orla-Jensen, S. (1919). The Lactic Acid Bacteria. Copenhagen: Host \& Sons.

Park, H. Y., Kim, K. K., Jin, L. \& Lee, S.-T. (2006). Microbacterium paludicola sp. nov., a novel xylanolytic bacterium isolated from swamp forest. Int J Syst Evol Microbiol 56, 535-539.

Rivas, R., Trujillo, M. E., Sánchez, M., Mateos, P. F., Martínez-Molina, E. \& Velázquez, E. (2004). Microbacterium ulmi sp. nov., a xylanolytic, phosphate-solubilizing bacterium isolated from sawdust of Ulmus nigra. Int J Syst Evol Microbiol 54, 513-517.

Schleifer, K. H. (1985). Analysis of the chemical composition and primary structure of murein. Meth Microbiol 18, 123-156.

Schleifer, K. H. \& Kandler, O. (1972). Peptidoglycan types of bacterial cell walls and their taxonomic implications. Bacteriol Rev 36, 407-477.

Takeuchi, M. \& Hatano, K. (1998). Union of the genera Microbacterium Orla-Jensen and Aureobacterium Collins et al. in a redefined genus Microbacterium. Int J Syst Bacteriol 48, 739-747.

Tamura, K., Dudley, J., Nei, M. \& Kumar, S. (2007). MEGA4: molecular evolutionary genetics analysis (MEGA) software version 4.0. Mol Biol Evol 24, 1596-1599.

Uchida, K., Kudo, T., Suzuki, K. I. \& Nakase, T. (1999). A new rapid method of glycolate test by diethyl ether extraction, which is applicable to a small amount of bacterial cells of less than one milligram. J Gen Appl Microbiol 45, 49-56.

Young, C.-C., Kämpfer, P., Shen, F.-T., Lai, W.-A. \& Arun, A. B. (2005). Chryseobacterium formosense sp. nov., isolated from the rhizosphere of Lactuca sativa L. (garden lettuce). Int J Syst Evol Microbiol 55, 423426.

Young, C.-C., Busse, H.-J., Langer, S., Chu, J.-N., Schumann, P., Arun, A. B., Shen, F.-T., Rekha, P. D. \& Kämpfer, P. (2010). Microbacterium agarici sp. nov., Microbacterium humi sp. nov. and Microbacterium pseudoresistens sp. nov., isolated from the base of the mushroom Agaricus blazei. Int J Syst Evol Microbiol 60, 854-860.

Ziemke, F., Höfle, M. G., Lalucat, J. \& Rosselló-Mora, R. (1998). Reclassification of Shewanella putrefaciens Owen's genomic group II as Shewanella baltica sp. nov. Int J Syst Bacteriol 48, 179-186.

Zlamala, C., Schumann, P., Kämpfer, P., Valens, M., Rosselló-Mora, R., Lubitz, W. \& Busse, H.-J. (2002). Microbacterium aerolatum sp. nov., isolated from the air in the 'Virgilkapelle' in Vienna. Int J Syst Evol Microbiol 52, 1229-1234. 